\title{
Síndrome de Burnout: Impacto da Satisfação no Trabalho e da Percepção de Suporte Organizacional
}

\author{
Vanessa Faria Neves \\ Áurea de Fátima Oliveira \\ Priscila Castro Alves \\ Universidade Federal de Uberlândia \\ Uberlândia, $M G$, Brasil
}

\begin{abstract}
RESUMO
Este estudo propôs-se a investigar um modelo em que as variáveis satisfação no trabalho e percepção de suporte organizacional consistem em preditoras da síndrome de burnout em profissionais de enfermagem. A amostra do estudo foi composta por 339 trabalhadores de enfermagem de um hospital universitário, que responderam um instrumento composto por dados sócio-demográficos e por escalas validadas das variáveis estudadas. Após realizadas as análises de regressão múltipla (método stepwise), constatou-se que os maiores percentuais de explicação para as três dimensões da síndrome de burnout foram atribuídos às variáveis satisfação com a natureza do trabalho e à percepção de suporte organizacional. Os resultados evidenciam a importância da natureza do trabalho e do apoio organizacional para esses profissionais e alertam para que as organizações de saúde lhes estabeleçam estratégias de valorização. A prevenção desta síndrome é fundamental para a garantia de um atendimento de qualidade aos usuários dos serviços de saúde.
\end{abstract}

Palavras-chave: Stress ocupacional. Satisfação no trabalho. Condições de trabalho.

\section{ABSTRACT}

\section{Burnout Syndrome: The Impact of Job Satisfaction and Perceived Organizational Support}

This study aimed to investigate a model in which the variables job satisfaction and perceived organizational support consist in predictors of the burnout syndrome in nurse professionals. The study sample consisted of 339 nurse staff of an university hospital, who answered an instrument composed of socio-demographic data and validated scales of the variables studied. After performing multiple regression analysis (stepwise method), it was found that the highest percentages of explanation for the three dimensions of burnout syndrome were assigned to the variables satisfaction with nature of the work and perceived organizational support. The results shows the importance of the nature of work and organizational support for these professionals and warns that health care organizations can establish strategies to value them. The prevention of this syndrome is critical to ensure a quality service to the users of health services.

Keywords: Occupational stress. Job satisfaction. Organizational support.

\section{RESUMEN}

\section{Síndrome de Burnout: El Impacto de la Satisfacción Laboral y Apoyo Organizacional Percibido}

Este estudio tuvo como objetivo investigar el modelo en el que la variables satisfacción en el trabajo y apoyo organizacional percibido consisten en predictores del síndrome de burnout en los profesionales de enfermería. La muestra del estudio consistió en 339 profesionales de enfermería de un hospital universitario, que respondieron a un instrumento compuesto de datos socio-demográficos y escalas validadas de las variables estudiadas. Después de realizar análisis de regresión múltiple (método stepwise), se encontró que los porcentajes más altos de la explicación de las tres dimensiones del síndrome de burnout fueron asignados a la variables satisfacción con la naturaleza del trabajo y el apoyo organizacional percibido. Los resultados muestran la importancia de la naturaleza del trabajo y el apoyo organizativo de estos profesionales y advierte de que las organizaciones de salud establecer estrategias para valorarlos. La prevención de este síndrome es fundamental para garantizar un servicio de calidad a los usuarios de los servicios de salud.

Palabras clave: Estres ocupacional. Satisfacción en el trabajo. Apoyo de la organización. 


\section{INTRODUÇÃO}

Ao longo do tempo o mundo do trabalho tem sofrido diversas transformações advindas de processos de globalização, aumento dos instrumentos tecnológicos, competitividade e perda do sentimento de coletividade tornando o ambiente profissional um lugar não propiciador da satisfação pessoal. Além disso, constata-se que o trabalho tem atingido elevadas proporções de desgaste físico e emocional (Maslach, Schaufeli e Leiter, 2001).

Nesse contexto, o burnout tem sido apontado como um problema social de grande relevância que vem sendo investigado em diversos países, uma vez que se encontra vinculado a custos organizacionais. Segundo Carlotto e Câmara (2008), alguns destes custos se devem à rotatividade de pessoal, absenteísmo, problemas de produtividade e qualidade e também por associar-se a vários tipos de disfunções pessoais, como o surgimento de graves transtornos psicológicos e físicos, o que pode levar o trabalhador à incapacidade total para o trabalho.

Neste estudo o burnout é concebido sob a perspectiva social psicológica de Maslach e Jackson, autoras que, em 1981, fizeram os primeiros estudos de caracterização desta síndrome, considerando-a não como um problema do indivíduo, mas do ambiente social em que o trabalhador está inserido. A estrutura e o funcionamento do local de trabalho ditam as formas pelas quais as pessoas interagem e como elas realizam suas tarefas. Quando a organização não é capaz de reconhecer o lado humano do trabalho e existem grandes incompatibilidades entre as exigências das tarefas e as habilidades e potencialidades do trabalhador para realizá-las, aumenta a probabilidade da ocorrência do burnout (Maslach, Schaufeli e Leiter, 2001; Maslach, 2006).

De acordo com a perspectiva social-psicológica, a síndrome de burnout é composta por três elementos centrais ou dimensões: exaustão emocional (caracterizada por sentimentos de desgaste emocional e esvaziamento afetivo, falta ou carência de energia e entusiasmo, sentimento de esgotamento de recursos); despersonalização (caracteriza-se por tratar o cliente, os colegas e a organização como objeto, por traduzir uma reação negativa, insensibilidade ou afastamento excessivo do público que deveria receber os serviços ou cuidados); diminuição da realização pessoal no trabalho (sentimento de diminuição de competência e de sucesso no trabalho, tendência do trabalhador a se auto-avaliar de forma negativa, sentimento de infelicidade consigo mesmo e insatisfação com seu desenvolvimento profissional) (Maslach e Jackson
1981, 1986; Maslach, 1993; Maslach, Schaufeli e Leiter, 2001).

No Brasil a síndrome de burnout passou a figurar como doença do trabalho em 1999, quando da Regulamentação da Previdência Social (Decreto, 1999; Benevides-Pereira, 2003). Em 2001 o Ministério da Saúde incluiu o burnout na relação de doenças ocupacionais classificando-a como um transtorno mental e do comportamento relacionado ao trabalho: CID-10 código Z73. 0 (Ministério da Saúde [MS], 2001).

A síndrome afeta principalmente profissionais da área de serviços ou cuidadores, principalmente quando o trabalho exige um contato diário, intenso e contínuo com os usuários, como no caso dos trabalhadores da educação, da saúde, policiais, assistentes sociais, agentes penitenciários, entre outros (Codo, 1999; Maslach, Schaufeli, e Leiter, 2001; MS, 2001). As pesquisas com profissionais de saúde evidenciaram que os profissionais mais investigados são os médicos, enfermeiros e assistentes de enfermagem (Matubaro; Lunardelli; Ellaro; Bulhões; Souza, 2009).

Os trabalhadores da área de saúde que atuam em instituições hospitalares estão expostos a diferentes estressores ocupacionais que afetam diretamente o seu bem estar. Dentre esses, exemplificam-se as longas jornadas de trabalho, o déficit de pessoal, a falta de reconhecimento profissional, a exposição a riscos químicos, físicos e biológicos, assim como o contato constante com o sofrimento, a dor e a morte. $\mathrm{O}$ desempenho destes profissionais envolve uma série de atividades que necessitam de um controle mental e emocional muito maior que em outras profissões (Benevides-Pereira, 2002).

Quando o burnout acomete profissionais que atuam na área hospitalar, torna-se uma realidade preocupante, pois na ocorrência desta forma de adoecimento profissional haverá comprometimento na qualidade da assistência prestada aos usuários dos serviços de saúde e a toda a rede social envolvida (Rosa e Carlotto, 2005). Dentre os estudos empíricos sobre o tema, encontram-se diversas pesquisas que abordam seu perfil epidemiológico, correlacionando-o com variáveis sociodemográficas (Carlotto e Palazzo, 2006; Ritter, Stumm e Kircher, 2009; Moreira, Magnago, Sakae e Magajewski, 2009; Santos, 2010).

Com relação aos estudos do burnout especificamente em trabalhadores de enfermagem, percebe-se que não há um consenso na literatura concernente aos níveis de prevalência e incidência dessa síndrome em trabalhadores da área. Há, contudo, uma clara tendência da existência de correlações estabelecidas entre o burnout e os dados sociofuncionais dos sujeitos 
acometidos por ela (Poncet et al., 2007; Silva e Carlotto, 2008; Silva, Loureiro e Peres, 2008; Carlotto, 2011; Ferrari, França e Magalhães, 2012).

Os resultados dessas pesquisas sobre burnout têm apontado ainda para a importância de se investigarem variáveis envolvidas na transação entre o indivíduo e o seu ambiente laboral, sobretudo porque há uma carência de pesquisas empíricas capazes de desvelar os antecedentes que atuam no desenvolvimento do burnout, testando variáveis como satisfação no trabalho, justiça organizacional, valores, percepções de suportes social e organizacional, dentre outras. Frente a essa lacuna apontada pela literatura, o presente trabalho optou por estudar as relações da satisfação no trabalho e a percepção de suporte organizacional com a síndrome de burnout.

A satisfação no trabalho representa a totalização do quanto o trabalhador vivencia experiências prazerosas no contexto das organizações, embora haja uma clara divergência quanto à definição desse constructo pelos estudiosos da área, sendo compreendido como aspecto motivacional, atitude e, atualmente, como afeto. Ao longo das últimas décadas mantiveram-se cinco de suas dimensões: satisfação com o salário, com os colegas de trabalho, com a chefia, com as promoções e com a natureza do trabalho (Siqueira, 2008).

As pesquisas têm demonstrado a relação entre satisfação e saúde no trabalho, particularmente, com a saúde mental (Martinez e Paraguay, 2003; Martinez, Paraguay e Latorre, 2004; Faragher, Cass e Cooper, 2005; Grazziano e Bianchi, 2010). Elevados índices de insatisfação com o trabalho podem produzir altos níveis de sofrimento mental, o que levaria o trabalhador a desenvolver síndromes ou doenças relacionadas ao trabalho, como o estresse ocupacional, doenças cardíacas e alérgicas e a síndrome de burnout (Martins e Santos, 2006).

De acordo com Ferreira e Assmar (2004), há estudos que tratam das relações entre as variadas características do trabalho e a satisfação, sendo que alguns têm analisado o papel desempenhado por aspectos específicos, como o suporte organizacional. A percepção de suporte organizacional (PSO) é um constructo definido por Eisenberger, Huntington, Hutchison e Sowa (1986) como "as crenças globais desenvolvidas pelo empregado sobre a extensão em que a organização valoriza as suas contribuições e cuida do seu bem-estar" (p. 501). Têm sido encontrados na literatura indícios de que esta percepção está fortemente relacionada à síndrome de burnout (Tamayo e Tróccoli, 2002).

A percepção do trabalhador sobre o suporte que a organização lhe oferece para desempenhar suas atividades poderia ser um fator determinante para a ocorrência do burnout. Nesse sentido, Aiken e Sloane (1997) e Grazziano e Bianchi (2010) afirmam que a síndrome de burnout se relaciona mais fortemente com os aspectos do ambiente de trabalho do que com características individuais dos empregados.

Essas variáveis, bem como a relação que se estabelece entre elas, constituem um tema relevante no contexto da saúde mental dos trabalhadores e das organizações hospitalares e, por isto, deve ser avaliado mais profundamente. Tendo em vista a escassa produção de trabalhos brasileiros acerca desta temática na área da enfermagem, e sua importância no contexto da psicologia social e do trabalho, este estudo analisou a relação entre satisfação no trabalho, percepção de suporte organizacional e síndrome de burnout, propondo um modelo de investigação em que as duas primeiras variáveis seriam antecedentes desta última. Como objetivos secundários, buscou-se verificar os níveis de satisfação no trabalho e percepção de suporte organizacional em todas as categorias profissionais da enfermagem estudadas.

\section{MÉTODO}

\section{Participantes}

A amostra foi composta por 339 trabalhadores de enfermagem de um Hospital Universitário no interior de Minas Gerais que voluntariamente participaram da pesquisa. Dentre esses profissionais, 229 (67,6\%) eram servidores públicos federais regidos pelo RJU (Regime Jurídico Único). Os demais trabalhadores eram celetistas, contratados via CLT (Consolidação das Leis do Trabalho) pela Fundação de apoio do hospital (Tabela 1).

Dentre os profissionais de enfermagem participantes desse estudo, constatou-se que a maioria era de técnico em enfermagem $(36,6 \% ; n=124)$. O tempo de formação profissional, assim como o tempo de trabalho na instituição variaram entre 1 e 35 anos, com médias de 14,4 anos $(D P=9,6)$ e 11,9 anos $(D P=8,8)$ respectivamente.

A maioria dos participantes $(81,1 \% ; n=275)$ pertencia ao sexo feminino, com idade média de 38,7 anos $(D P=9,7)$, sendo a idade mínima de 20 anos e a máxima de 60 anos, confirmando que a enfermagem ainda hoje é uma profissão predominantemente feminina. Tal fato se deve ao contexto histórico do surgimento da profissão, sendo também coerente com os resultados de outras pesquisas em que o sexo feminino representa mais de $80,0 \%$ da amostra estudada (Moreira et al., 2009; Meneghini, Paz e Lautert, 2011; Chaves, Ramos e Figueiredo, 2011). 
TABELA 1

Descrição da amostra

\begin{tabular}{llcc}
\hline $\begin{array}{c}\text { Dados de } \\
\text { identificação }\end{array}$ & \multicolumn{1}{c}{ Categoria } & $f$ & $\%$ \\
\hline $\begin{array}{l}\text { Número de } \\
\text { participantes }\end{array}$ & & 339 & 100 \\
Sexo & Masculino & 64 & 18,9 \\
& Feminino & 275 & 81,1 \\
Estado Civil & Solteiro & 111 & 32,7 \\
& Casado/vive junto & 180 & 53,1 \\
& Viúvo & 2 & 0,6 \\
& Desquitado/divorciado & 44 & 13,0 \\
& Em branco & 2 & 0,6 \\
Regime de & Estatutário & 229 & 67,6 \\
contratação & Celetista & 110 & 32,4 \\
Categoria & Enfermeiro & 108 & 31,9 \\
funcional & Técnico de enfermagem & 124 & 36,6 \\
& Auxiliar de enfermagem & 107 & 31,6 \\
Turno de & Manhã & 103 & 30,4 \\
trabalho & Tarde & 85 & 25,1 \\
& Diurno (12x36) & 47 & 13,9 \\
& Noturno (12x36) & 99 & 29,2 \\
& Em branco & 5 & 1,5 \\
\hline
\end{tabular}

\section{Definição das variáveis do estudo}

\section{Satisfação no trabalho}

A expressão "satisfação no trabalho" representa a totalização do quanto o indivíduo que trabalha vivencia experiências prazerosas no contexto das organizações (Siqueira, 2008). As fontes ou origens dessas experiências são atribuídas a cinco dimensões: (a) Satisfação com os colegas: reflete o contentamento com a colaboração, a amizade, a confiança e o relacionamento mantido com os colegas de trabalho; (b) Satisfação com o salário: se refere ao contentamento com o que recebe como salário se comparado com o quanto o indivíduo trabalha, com sua capacidade profissional, com o custo de vida e com os esforços feitos na realização do trabalho; (c) Satisfação com a chefia: diz respeito ao contentamento com a organização e a capacidade profissional do chefe, com o seu interesse pelo trabalho dos subordinados e o entendimento entre eles. (d) Satisfação com a natureza do trabalho: reflete o contentamento com o interesse despertado pelas tarefas, com a capacidade de absorverem o trabalhador e com a sua variedade; (e) Satisfação com as promoções: denota o contentamento com o número de vezes em que já recebeu promoções, com as garantias oferecidas a quem é promovido, com a maneira de a organização realizar promoções e por seu consequente tempo de espera por ela.

\section{Percepção de suporte organizacional}

"Crenças globais desenvolvidas pelo empregado sobre a extensão em que a organização valoriza as suas contribuições e cuida do seu bem-estar" (Eisenberger et al., 1986, p. 501).

\section{Sindrome de Burnout}

Trata-se de uma experiência subjetiva interna que gera sentimentos e atitudes negativas no relacionamento do indivíduo com o seu trabalho (insatisfação, desgaste e perda do comprometimento) (Tamayo e Tróccoli, 2002, 2009). O burnout é caracterizado pelas dimensões: Exaustão emocional que reflete a ideia de esgotamento, cansaço e desgaste no trabalho; Desumanização: refere-se à dureza emocional, desinteresse e atitudes negativas no contato com os clientes; e Decepção no trabalho: relaciona-se à insatisfação e falta de compromisso no trabalho, à desesperança com respeito ao progresso profissional e a perda da confiança na própria capacidade para realizá-lo adequadamente.

\section{Instrumentos}

Os dados foram coletados utilizando-se instrumentos fidedignos e válidos, conforme descrito a seguir:

Escala de Satisfação no Trabalho (Siqueira, 1995): é um instrumento multifatorial composto por 15 itens que devem ser avaliados em uma escala de sete pontos, tipo Likert, variando de 1 (totalmente insatisfeito) a 7 (totalmente satisfeito), com ponto médio em 4 (indiferente). A escala engloba as dimensões satisfação com os colegas de trabalho, com o salário, com a chefia, com a natureza do trabalho e com a promoção. Os coeficientes de fidedignidade variam entre 0,77 a 0,90 .

Escala de Percepção de Suporte Organizacional (Siqueira, 1995, 2008): instrumento unifatorial composto por 6 itens que devem ser avaliados em uma escala de sete pontos, tipo Likert, variando de 1 (discordo totalmente) a 7 (concordo totalmente), e ponto médio em 4 (nem concordo e em nem discordo), cujo índice de confiabilidade é igual a 0,86 .

Escala de Caracterização do Burnout (Tamayo e Tróccoli, 2009): composta por 35 afirmações sobre sentimentos e atitudes frente ao trabalho, que englobam as três dimensões da síndrome (exaustão emocional, desumanização e decepção no trabalho), que devem ser avaliadas em uma escala de frequência de cinco pontos, variando de 1 (nunca) a 5 (sempre), e ponto médio em 3 (algumas vezes). Os índices de confiabilidade variam de 0,84 a 0,93 . 


\section{Procedimentos de coleta de dados}

Trata-se de um estudo transversal, quantitativo, realizado em uma única instituição, submetido à apreciação e à aprovação do Comitê de Ética e Pesquisa (CEP) da Universidade Federal de Uberlândia, seguindo as normas da Resolução $n^{\circ} 196 / 96$ do CNS para realização de pesquisa com seres humanos (Análise final $n^{\circ} 1000 / 10$, protocolo de registro $\left.n^{\circ} 495 / 10\right)$. A coleta de dados foi realizada no final do ano de 2010 e início do ano de 2011, de maneira individual, sendo que os participantes responderam voluntariamente ao instrumento de coleta de dados em seu próprio local de trabalho.

\section{Procedimentos de análise de dados}

Para análise dos dados, utilizou-se o programa estatístico SPSS (Statistical Package of Social Science, versão 12.0). As estatísticas descritivas (média, frequência e desvio padrão) foram utilizadas para descrever a amostra e verificar os níveis de satisfação no trabalho, percepção de suporte organizacional e das dimensões da síndrome de burnout na amostra.

Os pressupostos necessários à aplicação da regressão múltipla foram verificados, incluindo a adequação do tamanho da amostra. $\mathrm{O}$ número de participantes do estudo atendeu ao critério da análise de regressão proposto por Miles e Shevlin (2001) e Tabachnick e Fidell (2001). Avaliou-se ainda o poder estatístico, que é determinado por três fatores: tamanho do efeito, alfa e tamanho da amostra (Hair, Anderson, Tatham e Black, 2005). A partir dos critérios propostos por Cohen (1977) realizou-se teste post-hoc, por meio do Programa GPower 3.1, compatível com as medidas de tamanho do efeito convencionadas por esse autor. Adotou-se como critério de significância $\alpha=0,05$ e efeito do tamanho da população (ES) grande para as análises que foram executadas, sendo constatado ainda tamanho de amostra adequado para as análises estatísticas realizadas.

Calculou-se o Alfa de Cronbach para cada escala do estudo na amostra investigada, cujos valores foram satisfatórios, variando de 0,73 a 0,94 (Hair et al., 2005). Em seguida foram calculados três modelos de regressão múltipla stepwise, tendo como variáveis independentes satisfação no trabalho (cinco fatores) e percepção de suporte organizacional e como variáveis dependentes as três dimensões da síndrome de burnout (exaustão emocional, desumanização e decepção no trabalho). A regressão múltipla stepwise é útil em estudos exploratórios (Abbad e Torres, 2002), sendo aqui utilizada posto que atende à proposta deste estudo.

\section{RESULTADOS}

\section{Análises descritivas}

Os valores das médias indicaram que os profissionais de enfermagem da instituição apresentaram níveis de satisfação com os colegas, chefia e natureza do trabalho acima do ponto médio da escala $(4,0)$, enquanto satisfação com salário e promoção obtiveram médias inferiores a esse ponto. A média de satisfação com a promoção foi de $3,03(D P=1,62)$, o que indica que os trabalhadores de enfermagem se sentem insatisfeitos com a forma de promoção da instituição. Com relação à satisfação com o salário, a média foi de 3,58 $(D P=1,62)$, evidenciando que esses trabalhadores se encontram entre insatisfeitos (ponto 3,0 da escala) a indiferentes (ponto 4,0 da escala) com o salário que recebem. A satisfação com a natureza do trabalho obteve média de $4,46(D P=1,13)$, valor próximo ao ponto 4,0 da escala, denotando indiferença. Por sua vez, a satisfação com colegas e chefia apresentaram, respectivamente, médias de 4,43 $(D P=1,04)$ e 4,80 $(D P=1,21)$, sugerindo que os trabalhadores de enfermagem se sentem indiferentes (ponto 4,0 da escala) a satisfeitos (ponto 5,0 da escala) com o relacionamento que mantêm com os colegas de trabalho e chefias.

Com relação à percepção de suporte organizacional, a equipe apresentou média de 2,64 $(D P=1,40)$. Logo, portanto, há evidências de que os participantes do estudo avaliaram negativamente o apoio e o suporte que recebem da organização para a qual trabalham.

Dentre as dimensões da síndrome de burnout, somente a exaustão emocional apresentou média acima do ponto médio da escala $(M=2,64 ; D P=0,85)$, um resultado indicador que os participantes admitem que, por algumas vezes, se sentem esgotados, cansados e desgastados com seu trabalho. As dimensões desumanização $(M=1,62 ; D P=0,51)$ e decepção no trabalho $(M=2,39 ; D P=0,60)$ obtiveram médias inferiores a 2,5, indicando que os trabalhadores de enfermagem deste hospital tendem raramente a agir com impessoalidade e frieza durante a assistência que prestam aos clientes, ou ainda, que raramente se sentem frustrados, desmotivados em função da profissão que escolheram.

\section{Análises de regressões múltiplas}

A Tabela 2 apresenta um resumo das três análises de regressão múltiplas stepwise para as três variáveis dependentes. Os resultados mostraram que a satisfação com a natureza do trabalho foi identificada como o melhor preditor da exaustão emocional $\left(R^{2}=0,291\right.$; $F(1,337)=138,133 ; p<0,01)$. A PSO também ofereceu sua contribuição, ainda que pequena $\left(R^{2}=0,052\right.$; 
TABELA 2

Resumo das três análises de regressão múltiplas stepwise para as variáveis dependentes exaustão emocional, desumanização e decepção no trabalho

\begin{tabular}{llccc}
\hline \multicolumn{1}{c}{ Variável dependente } & \multicolumn{1}{c}{ Preditores } & $R^{2}$ ajustado & $B$ & B padronizado \\
\hline Exaustão emocional & Sat. natureza trabalho & 0,291 & $-0,304$ & $-0,403$ \\
& PSO & 0,052 & $-0,145$ & $-0,238$ \\
& Sat. salário & 0,008 & $-0,053$ & $-0,101$ \\
& $R^{2}=0,351^{*}$ & & & $-0,187$ \\
Desumanização & Sat. natureza trabalho & 0,066 & $-0,84$ & $-0,176$ \\
& PSO & 0,026 & $-0,64$ & $-0,377$ \\
Decepção no trabalho & $R^{2}=0,092^{*}$ & & & $-0,270$ \\
& Sat. natureza trabalho & 0,282 & $-0,200$ & $-0,107$ \\
& PSO & 0,072 & $-0,115$ & $-0,044$ \\
& Sat. promoção & 0,009 & & \\
$p<0,05 ; * p<0,01$. & $R^{2}=0,363^{*}$ & & &
\end{tabular}

$F(1,336)=26,635 ; p<0,01)$, bem como a satisfação com o salário $\left(R^{2}=0,008 ; F(1,335)=4,276 ; p<0,01\right)$. Este modelo foi explicado em $35,1 \%$, incluindo essas três variáveis.

A desumanização apresentou dois preditores, explicando em $9,2 \%$ o modelo. A satisfação com a natureza do trabalho foi o principal preditor $\left(R^{2}=0,066\right.$; $F(1,337)=23,689 ; p<0,01)$, sendo a PSO o preditor com menor percentual de explicação $\left(R^{2}=0,026\right.$; $F(1,336)=9,712 ; p \leq 0,01)$. Na última análise de regressão, buscou-se identificar os preditores para a dimensão decepção no trabalho da síndrome de burnout. Encontrou-se novamente a satisfação com a natureza do trabalho como preditor de maior explicação $\left(R^{2}=0,282 ; F(1,337)=132,456 ; p \leq 0,01\right)$, seguido por PSO $\left(R^{2}=0,072 ; F(1,336)=37,608 ; p \leq 0,01\right)$ e satisfação com a promoção com um menor índice $\left(R^{2}=0,009\right.$; $F(1,335)=4,638 ; p<0,01)$, sendo que as três variáveis explicam $36,3 \%$ desse modelo.

\section{DISCUSSÃO}

As análises descritivas indicaram que os trabalhadores de enfermagem do hospital se sentem insatisfeitos com a forma de promoção da instituição. Esse resultado pode ser, em parte, explicado pelo fato de que a fundação que contrata funcionários de vínculo celetista não possuía até a ocasião da coleta de dados um plano de carreira para seus trabalhadores.

Os profissionais de enfermagem se sentem de insatisfeitos a indiferentes com o salário que recebem. A diferença salarial e de benefícios entre celetistas e estatutários pode ter contribuído para essa insatisfação. Além disso, é comum na literatura que as pessoas relatem insatisfação com seus ganhos, o que pode refletir expectativas elevadas que não correspondem aos seus ganhos reais.
O estudo de Schmidt e Dantas (2006) realizado com profissionais de enfermagem de quatro hospitais do Estado do Paraná revelou resultado semelhante, uma vez que a remuneração foi considerada como fonte de menor satisfação entre os trabalhadores, enquanto o status profissional, o de maior satisfação. $\mathrm{O}$ status profissional enquanto determinante da satisfação profissional nesse estudo, demonstra a importância do reconhecimento e respeito por parte da equipe e pacientes com relação ao trabalho realizado pela enfermagem.

$\mathrm{Na}$ direção oposta à literatura, os participantes desse estudo se mostraram indiferentes quanto à satisfação com a natureza do trabalho. Os estudos apontam os aspectos intrínsecos do trabalho como aqueles que detêm os melhores índices de satisfação (Silva, Beck, Guido, Lopes e Santos, 2009; Ruviaro e Bardagi, 2010).

Em se tratando da satisfação com colegas e chefias os sentimentos vão da indiferença à satisfação. Resultado análogo foi encontrado por Ruviaro e Bardagi (2010), em que a satisfação com a chefia foi percebida na maior parte dos setores da instituição. Por sua vez, Larraguibel e Paravic (2003), ao investigarem o nível de satisfação laboral de enfermeiras chilenas também identificaram que a interação com colegas e supervisores obteve o maior grau de satisfação entre pesquisados.

Os participantes do estudo não percebem apoio e suporte suficientes da organização para a qual trabalham. Estudo anterior realizado na mesma instituição em que este estudo foi concretizado, já indicava essa percepção negativa dos profissionais de enfermagem mediante o discurso de que a instituição não provia cuidados a seus empregados (Elias e Navarro, 2006). Embora o estudo não tratasse da percepção de suporte organizacional, mas sim das relações entre trabalho, saúde e condições 
de vida daqueles profissionais, o resultado é coerente com o conceito que é centrado na valorização e bem estar no trabalho.

Dentre as variáveis da síndrome de burnout, a exaustão emocional foi a que apresentou maior valor de média, portanto, em consonância com outros estudos. Esse resultado pode ser atribuído ao fato dessa dimensão tratar do estresse individual e de ser a mais representativa da síndrome. Assim, as pessoas descrevem a sua experiência com o burnout a partir dos seus sentimentos de exaustão (Maslach, Schaufeli e Leiter, 2001; Tamayo e Tróccoli, 2009). Outra explicação consistiria em que a exaustão emocional é uma das primeiras manifestações no processo do burnout (Maslach e Jackson, 1986).

Em relação à identificação dos preditores de burnout, objetivo principal deste estudo, os resultados mostraram que a satisfação com a natureza do trabalho mostrou-se como o melhor preditor de exaustão emocional, desumanização e decepção no trabalho, em uma relação inversa. À medida que diminui a satisfação com o trabalho realizado, aumenta-se a possibilidade de burnout. Resultado semelhante foi encontrado no caso da percepção de suporte organizacional, ou seja, relação inversa entre essa percepção e todas as dimensões de burnout. Os resultados do estudo de Oliveira, Tristão e Neiva (2006) com profissionais de Unidade de Terapia Intensiva (UTI) neonatal reforçam a ideia de que a síndrome de burnout é o resultado das dinâmicas entre a organização e o indivíduo, portanto, o apoio e a valorização percebidos afetam a vivência dessa síndrome. Schmidt, Paladini, Biato, Pais e Oliveira (2013), por sua vez, constataram em seu estudo que quanto menor a qualidade de vida no trabalho maior a exaustão emocional percebida pelos trabalhadores de enfermagem de UTI.

Há abordagens do burnout (Maslach e Leiter, 1997) que explicam a síndrome a partir de interpretações de desajuste indivíduo-trabalho. Quando a natureza do trabalho não está em harmonia com a natureza das pessoas, aumenta a probabilidade de desenvolvimento do burnout. De acordo com Maslach (2000, citado por Tamayo, 2009) as áreas ou fontes de desajustes são: sobrecarga, falta de controle, recompensas insuficientes, ausência de coleguismo, falta de justiça, conflito de valores. Tamayo (2009) evidenciou a relação entre o burnout e essas fontes organizacionais de desajuste: a ausência de coleguismo, sobrecarga de trabalho e conflito de valores e práticas organizacionais revelaram-se preditores significativos para exaustão emocional; o fator desumanização foi predito por sobrecarga de trabalho e o fator decepção no trabalho por ausência de coleguismo e sobrecarga de trabalho.
Novamente destaca-se aqui a importância da natureza das atividades desempenhadas e de uma percepção positiva do suporte organizacional, fatores esses mencionados neste estudo como preditores do burnout. A instituição deve suprir os profissionais de enfermagem com estrutura e recursos adequados para o bom desenvolvimento de suas atividades, já que estas, por sua natureza, implicam em contato com a dor e a morte.

Satisfação com o salário e as promoções foram preditores menos importantes de exaustão emocional e decepção no trabalho, respectivamente. No caso da primeira variável há respaldo do estudo de Schmidt e Dantas (2006), sendo remuneração a fonte de menor satisfação entre os trabalhadores, enquanto o status profissional, o de maior satisfação. Contudo, no estudo de Carlotto e Câmara (2007), com professores universitários a satisfação com o salário foi o preditor mais forte na explicação de exaustão emocional. Em contrapartida, para os professores não-universitários, as autoras identificaram que a satisfação com o crescimento foi a variável de maior poder explicativo para as três dimensões de burnout. Dessa forma, pressupõe-se que estar satisfeito com os rumos da carreira profissional é uma variável que atenua o burnout. Embora esse estudo adote instrumento de medida da satisfação no trabalho distinto, entende-se que a satisfação com o crescimento é análoga à satisfação com a promoção, que nesse estudo foi preditora da decepção no trabalho. Percebese, então, que em relação aos trabalhos supracitados não há clareza quanto aos determinantes dessa síndrome. Possivelmente, a categoria profissional possa ser uma variável importante a ser considerada.

As análises de regressão confirmaram a adequação do modelo investigado e mostraram que a satisfação com a natureza do trabalho e a PSO são os preditores prevalentes. Esse resultado em que a satisfação com a natureza do trabalho ocupa o papel central na predição do burnout pode ser pensado a partir da representação social da profissão de enfermagem.

De acordo com Collière (2003), a enfermagem é uma profissão de fé, que tem como escopo o "servir". Espera-se desse profissional dedicação, zelo, espírito de sacrifício e caridade, qualidades que garantam uma obrigação moral ou dever de serviços fundamentados em uma vocação, próxima da vocação religiosa. No entanto, há de se lembrar que esses profissionais estão expostos diariamente a situações de doenças e morte, desafios que exigem, além de conhecimento técnico e habilidades, preparo emocional para lidar com o sofrimento, a tristeza e a tensão decorrentes de tais situações. Aliado a isso, deve-se levar em consideração o contexto organizacional em que estão inseridos esses 
profissionais, que nem sempre oferece as condições ideais, ou sequer mínimas, para que seja realizado um trabalho adequado e de qualidade (Oliveira et al., 2006; Schmidt et al. (2013) .

Esta situação gera conflito, pois o profissional se vê à frente de inúmeras demandas de seus pacientes, porém não consegue atendê-las em sua totalidade, acarretando sentimentos de impotência e frustração com seu trabalho. E quando os recursos pessoais são insuficientes ou inadequados para atender as demandas, ocorre o burnout (Codo e Vasques-Menezes, 2002).

Como foi demonstrado neste estudo, também enfatizado em outras pesquisas, há uma relação entre satisfação e saúde mental no trabalho, uma vez que altos índices de insatisfação no trabalho produzem altos níveis de sofrimento mental, que podem levar ao desenvolvimento de doenças relacionadas ao trabalho, como estresse ocupacional, síndrome de burnout, dentre outras, que afetam seriamente a qualidade de vida do trabalhador (Martinez e Paraguay, 2003; Martinez et al., 2004; Faragher et al., 2005).

Palazzo, Carlotto e Aerts (2012), pesquisando sobre o burnout em servidores públicos, também descobriram que a percepção do ambiente de trabalho tem um importante papel preditor na síndrome. Tais constatações reforçam o argumento de Aiken e Sloane (1997) de que o burnout está mais relacionado a características do ambiente de trabalho do que a características do trabalhador. Percebe-se, assim, a importância do ambiente de trabalho, representado por meio de recursos humanos ou materiais, na manifestação da síndrome de burnout. Quanto melhor for percebido esse ambiente e as relações interpessoais que nele se estabelecem, mais satisfeito se encontrará o profissional e menos propenso ele estará ao burnout.

\section{CONSIDERAÇÕES FINAIS}

Este trabalho teve por objetivo principal verificar o impacto das variáveis satisfação no trabalho e percepção de suporte organizacional sobre a síndrome de burnout em trabalhadores de enfermagem de um Hospital Universitário do interior de Minas Gerais. Buscou-se também verificar os níveis de satisfação no trabalho e percepção de suporte organizacional em todas as categorias profissionais da enfermagem (enfermeiros, técnicos e auxiliares de enfermagem).

No que se refere ao nível de satisfação no trabalho, foi comprovado que os profissionais de enfermagem deste estudo apresentam-se insatisfeitos com os critérios adotados pela instituição para promoção e de insatisfeitos a indiferentes com o salário que recebem.
Os dados do estudo sinalizam para a insatisfação, o que constitui um alerta a ser considerado pela instituição visando ao bem-estar dessa categoria profissional, essencial para o funcionamento do hospital universitário. Com relação à percepção de suporte organizacional, constatou-se que os profissionais de enfermagem não percebem que a instituição para a qual trabalham esteja realmente comprometida com seus colaboradores. Tal fato aponta a necessidade premente de que os gestores de recursos humanos se mobilizem, buscando meios para recuperar o equilíbrio entre as expectativas do indivíduo e da organização, pois o trabalhador somente desenvolve percepções favoráveis acerca do suporte organizacional quando considera ser retribuído pela organização mediante o esforço despendido por ele em seu trabalho.

No que se refere ao objetivo principal, este foi alcançado. Por meio do modelo testado foi possível estabelecer o impacto das variáveis satisfação com a natureza do trabalho e percepção de suporte organizacional sobre a síndrome de burnout. Com esse resultado, percebe-se a importância da satisfação com os fatores intrínsecos ao trabalho para os profissionais de enfermagem da instituição, bem como de apoio organizacional, como fatores atenuantes do aparecimento da síndrome de burnout. A satisfação com a natureza do trabalho e a PSO se mostraram como os preditores prevalentes e apareceram em todos os modelos de regressão. Considerando os resultados obtidos, parece ser válida a ideia de que os trabalhadores de enfermagem, sentindo-se satisfeitos com a natureza das tarefas que lhes competem e percebendo que a organização para a qual trabalham se compromete e apoia seus colaboradores tendem a ser menos acometidos por essa síndrome.

Finalmente, o estudo apresentou resultados importantes e que podem contribuir para outras investigações acerca das variáveis aqui discutidas. Todavia, os resultados apontam a necessidade de novas pesquisas com profissionais de enfermagem, sobretudo porque aqueles aqui reportados dizem respeito à amostra de uma instituição hospitalar em particular e, portanto, não devem ser generalizados.

\section{REFERÊNCIAS}

Abbad, G., \& Torres, C. V. (2002). Regressão múltipla stepwise e hierárquica em psicologia organizacional: aplicações, problemas e soluções. Estudos de Psicologia (Natal), 7(esp.), 19-29.

Aiken. L. H., \& Sloane, D. M. (1997). Effects of organizational innovations in aids care on burnout among urban hospital nurses. Work and Occupations, 24, 453-477.

Benevides-Pereira, A. M. (2002). Burnout: quando o trabalho ameaça o bem-estar do trabalhador. São Paulo: Casa do Psicólogo. 
Benevides-Pereira, A.M.T. (2003). O Estado da Arte do Burnout no Brasil. Revista Eletrônica InterAção Psy, 1(1), 4-11.

Carlotto, M. S. (2011). Fatores de risco da síndrome de burnout em técnicos de enfermagem. Revista da SBPH, 14(2), 7-26.

Carlotto, M. S., \& Câmara, S. G. (2007). Preditores da Síndrome de Burnout em professores. Revista Semestral da Associação Brasileira de Psicologia Escolar e Educacional (ABRAPEE). 11(1), 101-110.

Carlotto, M. S., \& Câmara, S. G. (2008). Análise da produção científica sobre a Síndrome de Burnout no Brasil. Revista Psico, PUCRS, 39(2), 152-158.

Carlotto, M. S., \& Palazzo, L. S. (2006). Síndrome de Burnout e fatores associados: um estudo epidemiológico com professores. Cadernos de Saúde Pública, 22(5), 1017-1026.

Chaves, L. D., Ramos, L. H., \& Figueiredo, E. N. (2011). Satisfação profissional de enfermeiros do trabalho no Brasil. Acta Paulista de Enfermagem, 24(4), 507-513.

Codo, W. (Coord.). (1999). Educação: carinho e trabalho. Petrópolis: Vozes.

Codo, W., \& Vasques-Menezes, I. (2002). O que é Burnout? In Wanderley Codo. (Org.). Educação: carinho e trabalho. Petrópolis, Rio de Janeiro: Vozes, 237-254.

Cohen, J. (1977). Statistical Power Analysis for the Behavioral Sciences. New York: Academic Press.

Colliére, M. F. (2003). Cuidar: a primeira arte da vida. Loures: Lusociência.

Decreto n. 3048 (1999, 6 de maio) - Aprova o Regulamento da Previdência Social, e dá outras providências. Brasília, DF: Presidência da República.

Eisenberger. R., Huntington. R., Hutchison. S., \& Sowa. D. (1986). Perceived organizational support. Journal of Applied Psvchologv, 7, 500-507.

Elias, M. A., \& Navarro, V. L. (2006). A relação entre o trabalho, a saúde e as condições de vida: negatividade e positividade no trabalho das profissionais de enfermagem de um hospital escola. Revista Latino-Americana de Enfermagem, 14(4), 517-525.

Faragher, E. B., Cass, M., \& Cooper, C. L. (2005). The relationship between job satisfaction and health: a meta-analysis. Occupational Environment Medicine, 62(2), 105-112.

Ferrari, R., França, F. M., \& Magalhães, J. (2012). Avaliação da síndrome de burnout em profissionais de saúde: uma revisão integrativa da literatura. Revista Eletrônica Gestão \& Saúde, $3,1150-1165$.

Ferreira, M. C., \& Assmar, E. M. L. (2004). Cultura, satisfação e saúde nas organizações. In Tamayo, A. (Org.). Cultura e saúde nas organizações (pp. 102-126). Porto Alegre: Artmed, 2004.

Grazziano, E. S., \& Ferraz, Bianchi, E. R. (2010). Impacto do stress ocupacional e burnout para enfermeiros. Enfermería Global, 18, $1-20$.

Hair, J. F., Anderson, R. E., Tatham, R. L., \& Black, W. C. (2005). Análise multivariada de dados. Trad. de Adonai, S. S.; Anselmo, C. N. Porto Alegre: Bookman.

Larraguibel, B. F., \& Paravic, T. (2003). Nivel de satisfação laboral em Enfermeras de hospitales públicos y privados de la provincia de Concepción, Chile. Revista Ciencia y Enfermeria, 9(2), 57-66.

Martinez, M. C., \& Paraguay, A. I. B. B. (2003). Satisfação e saúde no trabalho: aspectos conceituais e metodológicos. Cadernos de Psicologia Social do Trabalho, 6, 59-78.

Martinez, M. C., Paraguay, A. I. B. B., \& Latorre, M. do R. D. de O. (2004). Relação entre satisfação com aspectos psicossociais e saúde dos trabalhadores. Revista de Saúde Pública, 38(1), 55-61.
Martins, M. C. F., \& Santos, G. E. (2006). Adaptação e validação de construto da Escala de Satisfação no Trabalho. Revista PsicoUSF, 11(2), 195-205.

Maslach, C. (1993). Burnout: A multidimensional perspective. In W. B. Schaufeli, C. Maslach, \& T. Marek (Eds.), Professional burnout: recent developments in theory and research (pp. 19-32). New York: Taylor \& Francis.

Maslach, C. (2006). Promovendo o envolvimento e reduzindo o burnout. In Anais do VI Congresso de Stress da ISMA-BR e VIII Fórum Internacional de Qualidade de Vida no Trabalho. Porto Alegre: CD-ROM.

Maslach, C., \& Jackson, S. E. (1981). The measurement of experienced burnout. Journal of Ocuppational Behavior, 2, 99-113.

Maslach, C., \& Jackson, S. E. (1986). Maslach Burnout Inventory, Manual. Palo Alto, University of California, Consulting Psychologist.

Maslach, C., \& Leiter, M. P. (1997). The truth about burnout: How organizations cause personal stress and what to do about it. San Francisco: Jossey Bass.

Maslach, C., Schaufeli, W. B., \& Leiter, M. P. (2001). Job Burnout. Annual Reviews of Psychology, 52, 397-422.

Matubaro, K. C. A, Lunardelli, M. C. F., Ellaro, A. M, Bulhões, L. F. S. S., \& Souza, L. L. (2009). A sindrome de burnout em profissionais da saúde: uma revisão bibliográfica. Acesso em 02 abril 2010, em: http://prope.unesp.br/xxi_cic/27_22891515803.pdf

Meneghini, F., Paz, A. A., \& Lautert, L. (2011). Fatores ocupacionais associados aos componentes da síndrome de burnout em trabalhadores de enfermagem. Texto Contexto Enfermagem, 20(2), 225-233.

Miles, J., \& Schevlin, M. (2001). Applying regression, \& correlation. A guide for students e researchers. London: Sage Publications.

Ministério da Saúde do Brasil. Organização Pan-Americana da Saúde no Brasil. (2001). Doenças relacionadas ao trabalho: manual de procedimentos para os serviços de saúde. Brasília, DF: Autor.

Moreira, D. de S., Magnago, R. F., Sakae, T. M., \& Magajewski, F. R. L. (2009). Prevalência da síndrome de burnout em trabalhadores de enfermagem de um hospital de grande porte da Região Sul do Brasil. Cad. Saúde Pública, 25(7), 1559-1568.

Oliveira, P. R., Tristão, R. M., \& Neiva, E. R. (2006). Burnout e suporte organizacional em profissionais de UTI-Neonatal. Educação Profissional: Ciência e Tecnologia, 1(1), 27-37.

Palazzo, L. dos S., Carlotto, M. S., \& Aerts, D. R. G. de C. (2012). Síndrome de burnout: estudo de base populacional com servidores do setor público. Revista de Saúde Pública, 46(6), 1066-1073.

Poncet, M. C., Toullic, P., Papazian, L., Kentish-Barnes, N., Timsit, J. F., Pochard, F., Chevret, S., Schlemmer, B., \& Azoulay, E. (2007). Burnout syndrome in critical care nursing staff. American Journal of Respiratory and Critical Care Medicine, 175(7), 698-704.

Ritter, R. S., Stumm, E. M. F., \& Kircher, R. M. (2009). Análise de Burnout em profissionais de uma unidade de emergência de um hospital geral. Revista Eletrônica de Enfermagem, 11(2), 236-248.

Rosa, C. da, \& Carlotto., M. S. (2005). Síndrome de burnout e satisfação no trabalho em profissionais de uma instituição hospitalar. Revista da Sociedade Brasileira de Psicologia Hospitalar (Belo Horizonte), 8(2), 1-15.

Ruviaro, M. de F. S., \& Bardagi, M. P. (2010). Síndrome de burnout e satisfação no trabalho em profissionais da área de enfermagem do interior do RS. Barbarói, 33, 194-216. 
Santos, P. G. (2010). O estresse e a síndrome de burnout em enfermeiros bombeiros atuantes em unidades de prontoatendimento (UPAS). Dissertação de mestrado, Universidade Federal do Estado do Rio de Janeiro, Rio de Janeiro.

Schmidt D. R. C., \& Dantas, R. A. S. (2006). Qualidade de vida no trabalho de profissionais de enfermagem, atuantes em unidades do bloco cirúrgico, sob a ótica da satisfação. Rev Latinoamericana de Enfermagem, 14(1), 54-60.

Schmidt, D. R. C., Paladini, M., Biato, C., Pais, J.D., \& Oliveira, A.R. (2013). Qualidade de vida no trabalho e burnout em trabalhadores de enfermagem de Unidade de Terapia Intensiva. Revista Brasileira de Enfermagem, 66(1), 13-27.

Silva R. M., Beck, C. L. C., Guido, L. A., Lopes, L. F D., \& Santos J. L. G. (2009). Análise quantitativa da satisfação profissional dos enfermeiros que atuam no período noturno. Texto Contexto - Enfermagem (Florianópolis), 18(2), 298-305.

Silva, D. C. M., Loureiro, M. de F., \& Peres, R. S. (2008). Burnout em profissionais de enfermagem no contexto hospitalar. Psicologia Hospitalar, 6(1), 39-51.

Silva, T. D., \& Carlotto, M. S. (2008). Síndrome de burnout em trabalhadores da enfermagem de um hospital geral. Revista SBPH, 11(1), 113-130.

Siqueira, M. M. M. (1995). Antecedentes de comportamento de cidadania organizacional: análise de um modelo pós-cognitivo. Tese de doutorado, Universidade de Brasília, DF.

Siqueira, M. M. M. (2008). Satisfação no trabalho. In Siqueira, M. M. M. (Org.). Medidas do comportamento organizacional: ferramentas de diagnóstico de gestão (pp. 265-274). Porto Alegre: Artmed.
Tabachnick, B. G., \& Fidell, L. S. (2001). Using multivariate statistics. New York: Harper and Row.

Tamayo, M. R. (2009). Burnout: Implicações das Fontes Organizacionais de Desajuste Indivíduo-Trabalho em Profissionais da Enfermagem. Psicologia: Reflexão e Crítica, 22(3), 474-482.

Tamayo, M. R., \& Tróccoli, B. T. (2009). Construção e validação fatorial da Escala de Caracterização do Burnout (ECB). Estudos de Psicologia, 14(3), 213-221.

Tamayo, M. R., \& Tróccoli, B. T. (2002). Exaustão emocional: relações com a percepção de suporte organizacional e com as estratégias de coping no trabalho. Estudos de Psicologia, 7(1), $37-46$

\section{Autores:}

Vanessa Faria Neves - Mestranda em Psicologia pela Universidade Federal de Uberlândia. Enfermeira do Hospital Universitário da Universidade Federal de Santa Catarina.

Áurea de Fátima Oliveira - Doutora em Psicologia. Professora do Programa de Pós-Graduação em Psicologia da Universidade Federal de Uberlândia.

Priscila Castro Alves - Mestre em Psicologia. Enfermeira da Universidade Federal de Uberlândia.

\section{Endereço para correspondência:}

Vanessa Faria Neves

Universidade Federal de Uberlândia

Av. Mato Grosso, 3424 - Umuarama

CEP: 38405-314 Uberlândia, MG, Brasil

E-mail: nesshaneves@yahoo.com.br

Recebido em: 09.09.2013.

Aceito em: 10.03.2014 